\title{
EDITORIAL
}

\section{Environmental control: an idea whose time has come}

\author{
A.B. Becker*, M. Chan-Yeung**
}

The importance of the relationship between asthma and allergy is now well-recognized [1-7]. Studies of asthmatic patients with house dust mite allergy have demonstrated the importance of house dust mite avoidance measures in the control of asthma [8-11]. MuRRAY and FERGUSON [8] showed that a "sterile" bedroom environment was associated with marked improvement in children with asthma due to house dust mite allergy. In adults with the same condition, PlatTs-Mills et al. [9] showed that airway responsiveness improved over a period of months in an allergen-free hospital environment. Residence at high altitude, where mite allergen levels are low, has also been used successfully in the treatment of asthma [10]. These and other unblinded, open studies in house dust mite-allergic patients have shown that aggressive measures to reduce house dust mite allergen exposure can improve asthma. Moreover, they suggest that sensitization and continuous exposure to an allergen are important risk factors for persistent asthma.

Although sensitivity to specific allergens has, for a long time, been demonstrated in vivo by epicutaneous testing, it is only recently that measurement of levels of exposure to allergen (such as house dust mite and cat) has been performed. The production of monoclonal antibodies to these allergens has provided us with tools to assess exposure to the allergens more accurately, and also to assess the efficacy of intervention measures [12, 13]. During the past decade, most studies have measured levels of allergen in dust samples collected from a variety of reservoirs, such as mattresses and carpets, that may not accurately reflect the actual levels of exposure that patients have to the allergen. More recently, measurement of allergen levels in air samples of respirable dust particles have been carried out in an attempt to relate exposure and asthma severity $[14,15]$. We now have the tools to study the dose-response relationship in order to better determine the levels of allergen exposure required for sensitization and for asthma exacerbations. Similarly, we should now be able to assess the change in allergen exposure with environmental control measures that is required to improve asthma.

The article by VAN DER HEIDE et al. [16] in this issue of the Journal, attempts to address various aspects of allergen exposure and asthma. The authors have studied the effects of high-efficiency air cleaners and impermeable mattress coverings (a well-proven method) in

The authors are members of Inspiraplex: Respiratory Health Network of Centres of Excellence. *Section of Allergy and Clinical Immunology, Dept of Pediatrics \& Child Health, University of Manitoba, Winnipeg, Manitoba, Canada. **Respiratory Division, Dept of Medicine, University of British Columbia, 2775 Heather St, Vancouver, B.C., V5Z $3 J 6$ Canada. reducing exposure to allergens and severity of asthma. Airway hyperresponsiveness was measured as a reflection of the severity of asthma. The authors demonstrated that "considerable amounts of airborne dust and allergenic particles were captured in the filters of the air cleaner". As with other studies, they found a significant decrease in house dust mite allergen from mattresses encased in an impermeable covering. Measurable house dust mite allergen was also entrapped at all levels of the air filters, but the amount of house dust mite allergen captured by the air filters was not related to the concentration in dust samples from the floor. The high efficiency particulate air (HEPA) component of the air filters captured cat allergen, even in homes without cats (at least in $60 \%$ of such homes). Improvement in airway hyperresponsiveness was found in the group treated with active air filters and mattress and pillow covers. A trend to improvement was also found in the group treated with mattress covers and inactive air filters. Thus, even in this relatively small group of allergic patients, the simple expediency of encasing one source of house dust mite allergen, the mattress, appears to have some impact on asthma.

Of particular interest in this study is the multiple regression analysis, in which improvement in airway hyperresponsiveness was found to relate to exposure to textile floor covering (carpeting) in the living room, to companion animals in the homes, and to the ability to greatly reduce house dust mite allergen in the mattress. This finding confirms the notion that high levels of allergen exposure are important in sustaining airway hyperresponsiveness in asthma. Furthermore, it defines the presence of a reservoir for allergen (a companion animal in the home and/or the presence of carpeting) as a major risk factor for ongoing asthma.

Environmental control is generally given "lip service" in asthma therapy. As the potential value for environmental therapy increases, we must give serious consideration to proper and effective means for environmental control. Compliance is not usually a problem with house dust mite avoidance measures. However, compliance is a major issue with companion animals, particularly with cats, which generate an important allergen throughout our communities. Given the psychosocial issues and the widespread exposure to cat allergen, issues of ventilation and filtration in the home and work environment will be of increasing importance. We must also consider carpeting as a risk factor for the development of allergy and asthma, and this must be reflected in our approach to home and office construction. Patients at high risk for these disorders should be counselled to avoid textile floor coverings in their home. Serious consideration should 
be given by the floor coverings industry to the development of textile floor coverings, which either prevent allergen from collecting, or which, rather than acting as simple reservoirs, act as traps, that hold, but do not release, allergen.

Proper and effective methods of ventilation and filtration in our homes and in our work environment must be the focus of increased research, particularly given the "epidemic" of allergy and asthma in the industrialized world since 1970. We now have at our disposal effective means to rigorously assess the impact of environment control on patients with asthma. Improved understanding of environmental control is critical in our approach to control of this major health problem.

\section{References}

1. Cockroft DW, Ruffin RE, Dolovich J, Hargreave FE. Allergen-induced increase in nonallergic bronchial reactivity. Clin Allergy 1977; 8: 503-513.

2. Boulet LP, Cartier A, Thomson NC, Roberts RS, Dolovich J, Hargreave FE. Asthma and increases in nonallergic bronchial responsiveness from seasonal pollen exposure. J Allergy Clin Immunol 1983; 71: 399-406.

3. Peak JK, Tovey E, Mellis CM, Leeder SR, Woolcock AJ. Importance of house dust mite and Alternaria allergy: an epidemiological study of children living in two climatic areas of northern New South Wales. Clin Exp Allergy 1993; 23: 812-820.

4. Sears MS, Hervison GP, Holdaway MD, Hewitt CJ, Flannery EM, Silva PA. The relative risks of sensitivity to grass pollen, house dust mite, and cat dander in the development of childhood asthma. Clin Exp Allergy 1989; 19: 419-424.

5. Sporik R, Holgate ST, Platts-Mills TAE, Cogswell J. Exposure to house dust mite allergen (Der $p$ 1) and the development of asthma in childhood: a prospective study. N Engl J Med 1990; 323: 502-507.

6. Charpin D, Birnbaum J, Haddi E, et al. Altitude and allergy to house dust mites. Am Rev Respir Dis 1991; 143: 983-986.
7. Warner JO, Price JF. House dust mites sensitivity in childhood asthma. Arch Dis Child 1978; 53: 710713.

8. Murray AB, Ferguson AC. Dust-free bedrooms in the treatment of asthmatic children with house dust or dust mite allergy: a controlled trial. Pediatrics 1983; 71: 418-422.

9. Platts-Mills TAE, Mitchell EB, Nock P, Tovey ER, Mosroro H, Wilkins SR. Reduction of bronchial hyperreactivity during prolonged allergen avoidance. Lancet 1982; ii: 675-678.

10. Boner AL, Nicro E, Antolini I, Valletta AE, Gaburro D. Pulmonary function and bronchial hyperreactivity in asthmatic children with house dust mite allergy during prolonged stay at in the Italian Alps (Misurina, 1756 m). Ann Allergy 1985; 54: 42-45.

11. Ehnert B, Lau-Schdendorf S, Weber A, Buettner P, Schou C, Wahn U. Reducing domestic exposure to dust mite allergen reduces bronchial hyperreactivity in sensitive children with asthma. J Allergy Clin Immunol 1992; 90: 135-138.

12. Luczynska CM, Arruda LK, Platts-Mills TAE, Miller JD, Lopez M, Chapman MD. A two-site monoclonal antibody ELISA for the quantitation of the major Dermatophagoides spp. allergens, Der $p 1$ and $\operatorname{Der} f 1 . J$ Immunol Methods 1989; 118: 227-235.

13. Ohman JL, Baer H, Anderson MC, et al. Surface washes of living cats: an improved method of obtaining clinically relevant allergen. J Allergy Clin Immunol 1983; 72: 288-292.

14. Luczynska CM, Li Y, Chapman MD, Platts-Mills TAE. Airborne concentrations and particle size distribution of allergen derived from domestic cats (Felis domesticus): measurements using cascade impactor, liquid impinger and a two-site monoclonal antibody assay for $\mathrm{Fel} d 1$. Am Rev Respir Dis 1990; 141: 361-367.

15. de Blay F, Chapman M, Platts-Mills T. Airborne concentrations and particle size distribution of allergen derived from domestic cats (Felis domesticus). Am Rev Respir Dis 1990; 141: 361-367.

16. van der Heide S, Kauffman HF, Dubois AEJ, de Monchy JGR. Allergen reduction measures in houses of allergic asthmatic patients. Eur Respir J 1997; 10: 1217-1223. 